\title{
Does chronic disease influence susceptibility to the effects of air pollution on depressive symptoms in China?
}

Qing Wang ${ }^{1 \dagger}$ and Zhiming Yang ${ }^{2^{*}}$ (D)

\begin{abstract}
Background: Exogenous stressors resulting from air pollution can lead to depression and chronic disease. Chinese levels of air pollution are among the highest in the world, and although associated adverse health effects are gradually emerging, research determining individual vulnerability is limited. This study estimated the association between air pollution and depressive symptoms and identified whether chronic disease influences an individual's susceptibility to depressive symptoms relating to air pollution.
\end{abstract}

Methods: Individual sample data from the China Health and Retirement Longitudinal Study and a group of city-level variables in 2011 and 2013 were used with the random effects model and Tobit model. Adjustments were made for demographic, socioeconomic status, health behavior, and city-level climate variables with respect to living areas. Analysis was also stratified using chronic disease characteristics.

Results: The total Center for Epidemiological Studies Depression scale evaluating depressive symptoms ranged between 7 and 28 [average $11.623(S D=4.664)$ ]. An 1\% increase in sulfur dioxide and total suspended particulate emission intensities was associated with depressive symptoms scores that were $1.266(\mathrm{SE}=0.107, \mathrm{P}<0.001,95 \% \mathrm{Cl}$ $1.057-1.475$ ) and 1.318 ( $\mathrm{SE}=0.082, \mathrm{P}<0.001,95 \% \mathrm{Cl} 1.157-1.480$ ) higher, respectively. Compared to respondents without chronic disease, those with chronic diseases such as hypertension, dyslipidemia, diabetes or high blood sugar, cardiovascular diseases, cancer or malignant tumor, liver disease, chronic lung diseases, kidney disease, stomach or other digestive disease, arthritis or rheumatism, and asthma had scores that were higher for depressive symptoms.

Conclusions: Results confirm that the adverse health effects of air pollution should be considered when developing air pollution policies. Findings also provide justification for mental health interventions targeting air pollution exposure, especially for people with chronic diseases.

Keywords: Air pollution, Depression, Chronic diseases, China

\section{Background}

The Chinese government encouraged the growth of industries and urbanization since 1978. However, the associated rapid economic development has caused environmental issues, and China is now one of the most polluted countries in the world [1-3]. For example, the

\footnotetext{
*Correspondence: yangzm@ustb.edu.cn

${ }^{\dagger}$ Qing Wang and Zhiming Yang are Joint first authors

2 Donlinks School of Economics and Management, University of Science and Technology Beijing, Beijing 100083, China

Full list of author information is available at the end of the article
}

annual average Total Suspended Particulates (TSP) concentration regularly exceeds $400 \mu \mathrm{g} / \mathrm{m}^{3}$ in China [4], which is significantly higher than that in large European cities (e.g. Oslo, $15 \mu \mathrm{g} / \mathrm{m}^{3}$; Marseille, $18 \mu \mathrm{g} / \mathrm{m}^{3}$ ) [5] and World Health Organization (WHO) primary $\left(80 \mu \mathrm{g} / \mathrm{m}^{3}\right)$ and secondary $\left(60 \mu \mathrm{g} / \mathrm{m}^{3}\right)$ standards $[6,7]$.

Air pollution is believed to be associated with depressive symptoms [8]. Potential biological mechanisms relating to depressive symptoms include reactivity to exogenous stressors; alterations of neurohumoral, immune, and autonomic regulation; dysfunction of neuro transmitter systems; and oxidative stress [9]. Cell 
cultures and experimental animals studies have shown neuropathological effects from air pollution exposure [10-12], and previous empirical studies have observed that air pollution increases the prevalence of depressive symptoms in Korea, Japan, and the Netherlands [8, 1315]. Furthermore, an increasing number of emergency department visits for depression in Canada and Korea have been documented [16, 17].

Depression is a serious problem in China [18, 19 ]: in 2013, 36 million years of healthy life were lost to mental illness in China, and estimates suggest that by $2025,39.6$ million years of healthy life will be lost $(10 \%$ increase) [20]. Although little is known about the association between air pollution and depression, several Chinese studies have found a relationship between exposure to air pollution and happiness [21, 22], depressive symptoms [23], cognitive functions [24, 25] and hospital admissions for mental disorders [26], when results were adjusted for demographics and socioeconomic status. It is considered that a further decline in air quality could cause an increased risk to health and an associated increase in depressive symptoms. Therefore, this study uses nationally representative data to estimate the association between air pollution and depression measured by the Center for Epidemiologic Studies Depression (CES-D) scale.

Air pollution regulations based on observed health effects in the general population may be insufficient to protect exceptionally vulnerable subgroups. Inconsistent study results have been found within past study cohorts. For example, no significant association between air pollution exposure and depressive symptoms was found in a Boston-area study [27], although other American studies reported that exposure to air pollution was related to anxiety symptoms [28], which often have a comorbidity with depression [29]. One American study found that stroke victims were more susceptible to the effects of air pollution with respect to cognitive functions [30]. Thus, it is believed that chronic disease (e.g. hypertension), which is often regarded as a marker of inflammation and vascular dysfunction, may mediate an association between air pollution and depressive symptoms [31,32]. Compared to people in good physical health, the well-known adverse mental health effects of air pollution may mean that respondents with chronic disease are likely to believe that their physical health is being damaged [33-35]. However, the role of an individual's physical health status in the association between air pollution and depression symptoms has not yet been addressed in China. Therefore, this study aims to assess which individuals have a greater vulnerability to the adverse effects of air pollution [21].

\section{Data and methods}

\section{Data}

Individual sample data and a group of city-level variables were obtained to evaluate the relationship between air pollution, chronic disease, and depressive symptoms. Individual data were collected from CHARLS 2011 and 2013, which were national representative surveys conducted with middle-aged and elderly Chinese residents (aged 45 years and above) using face-to-face computerassisted personal interviews. The CHARLS questionnaire included the following modules: demographics, family structure/transfer, health status and functioning, biomarkers, health care and insurance, work, retirement and pension, income and consumption, assets (individual and household), and community-level information. These surveys were approved by the ethics committee of the Institutional Review Board of Peking University.

Using multi-stage stratified probability-proportionateto-size sampling, the sample in CHARLS represented approximately 10,000 households in 150 counties/districts (a total of 450 villages/resident communities). The baseline survey was conducted between June 2011 and March 2012 with a response rate of $80.5 \%$ and a total sample of 17,545 respondents. A total of $15,020(86 \%)$ respondents participated in the follow-up survey in 2013, but 2525 (14\%) respondents had died or declined participation in the study. In this study, CHARLS 2011 and 2013 panel data were constructed to estimate the relationship between air pollution and depressive symptoms for 15,020 respondents $(15,020 \times 2=30,040$ samples $)$. Of the respondents, $47 \%$ were male with a mean age of 60 years. Ages and gender distribution were very similar to those in the 6th national census conducted in 2010 [36].

City-level variables included monthly temperature, monthly relative humidity, and annual air pollution. Daily meteorological data from 839 stations in 2011 and 2013 were collected from the China Meteorological Science Data Sharing Service Network-China Ground Climate Daily Data. The station-level data were aggregated at a city level by matching stations to the closest city based on the exact longitude and latitude of the weather station and the longitude and latitude of the county centroid. The average monthly temperature and relative humidity of CHARLS 125 sample cities were then calculated from daily data. Based on survey city and month, the results from 15,020 respondents in the two CHARLS waves were combined with the meteorological data from 125 cities.

The annual sulfur dioxide $\left(\mathrm{SO}_{2}\right)$ and TSP emissions from 273 cities in 2011 and 2013 were obtained from the 2012 and 2014 China City Statistical Yearbook. Based on survey year and city, 12,046 respondents of the 15,020 respondents in the two CHARLS waves were matched to the air pollution data from 101 cities. After excluding 412 
respondents that provided missing values from 12,046 respondents, 11,634 respondents were included, and the final sample size was $23,268(11,634 \times 2)$ samples from 101 cities. Figure 1 presents a flow chart of the study process.

\section{Variables}

\section{Depressive symptoms}

A modified seven-item version of the CES-D scale was constructed to measure depressive symptoms [37]. Respondents reported the frequency of experiencing the following seven depressive symptoms during the past week: (1) "was bothered by things," (2) "had trouble keeping mind on what was doing," (3) "felt depressed," (4) "felt everything he/she did was an effort," (5) "felt fearful," (6) "sleep was restless," and (7) "felt lonely." Each answer was encoded from 1 to $4: 1=$ rarely or none, $2=$ some or a little, $3=$ occasionally or a moderate amount, and $4=$ most or all of the time, with total scores ranging from 7 to 28. A summed score of the seven items was calculated, with lower scores indicating fewer depressive symptoms. This shortened seven-item CES-D scale is a widely used indicator for depressive symptoms [38, 39]. Its validity, reliability, and cultural equivalence have been proven in China [40]. In our data set, CES-D was also demonstrated to have high internal consistency (Cronbach's alpha $=0.82$ ) and to construct validity (Kaiser-MeyerOlkin $=0.87$ ) according to the standards of Meulen et al. [41], Kara [42], and Aly [43], which suggest that if the Cronbach's alpha and Kaiser-Meyer-Olkin test value exceeds the recommended level of 0.70 then data is considered to be highly reliable [41-43].

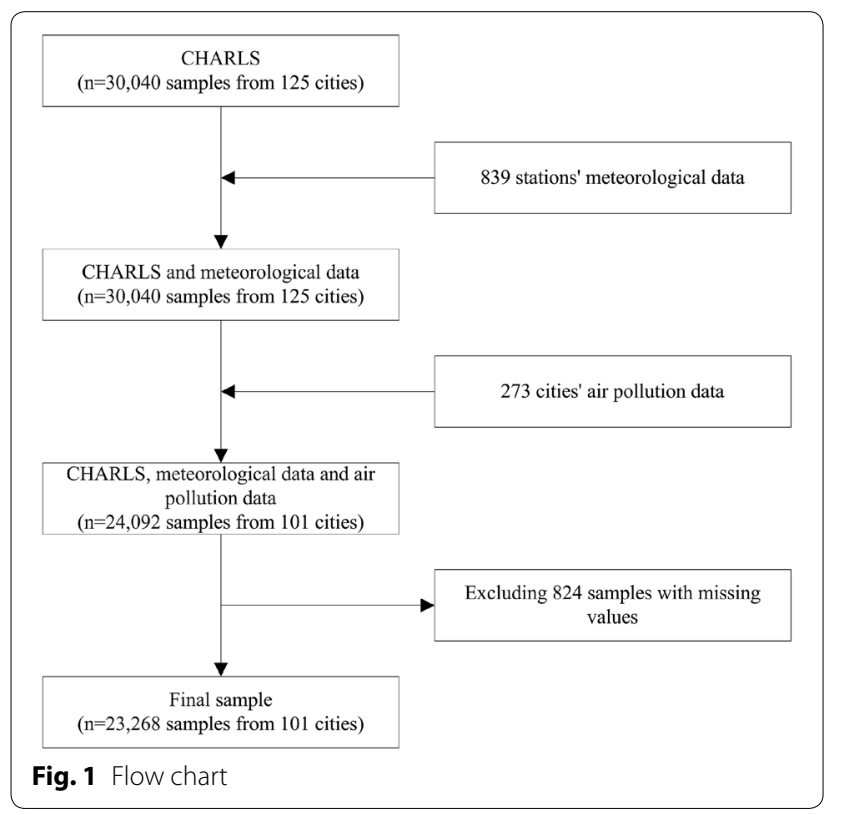

\section{Air pollution}

Following previous studies, $\mathrm{SO}_{2}$ and TSP emission intensity, $\mathrm{SO}_{2}$ and TSP emissions per capita, and $\mathrm{SO}_{2}$ and TSP emissions per unit area were calculated to measure air pollution [44-47]. Pollution intensity refers to the indicator of pollution emissions per industrial gross domestic product (GDP) (industrial economic output). Log transformation of air pollution data was applied to minimize skewness [45].

\section{Chronic disease}

A categorical variable for a doctor to use in diagnosing chronic disease was created based on the question, "Have you ever been diagnosed with hypertension, dyslipidemia, diabetes or high blood sugar, cardiovascular disease (heart attack, coronary heart disease, angina, congestive heart failure, stroke or other heart problems), cancer or malignant tumor, liver disease, chronic lung disease, kidney disease, stomach or other digestive disease, arthritis or rheumatism and asthma by a doctor?" The variable equaled 1 or 0 for respective replied of "yes" or "no".

\section{Estimation Strategy}

Descriptive analysis was first conducted to describe sample characteristics of the total sample and for chronic disease status. Frequencies with percentages were presented for categorical variables (gender, marital status, education, employment status, insurance status) and means with standard deviations for continuous variables (CES$\mathrm{D}$, air pollution indicators, climate indices, income, and age). P-values were calculated using the Chi square test for categorical variables, and one-way Analysis of Variance (ANOVA) for continuous variables between groups (with or without chronic disease).

A random effects model was then applied to link air pollution intensity with depressive symptoms. Omitted variable bias was controlled using the random effects model. The individual random effects model is presented as follows,

$$
\text { Depressive }_{i j t}=a_{0}+\text { Air }_{j t} a_{1}+X_{i j t} a_{2}+u_{i}+v_{t}+e_{i j t},
$$

where $a_{0}, a_{1}, a_{2}$ are the parameters to be estimated; $u_{i}$ and $v_{t}$ are the individual effects and year fixed effects, respectively; $e_{i j t}$ is the idiosyncratic error term; and Depressive $_{i j t}$ is the depressive symptoms of person $i$ in city $j$ in year $t ; A i r_{j t}$ is a variable indicating the log of air pollution intensity, $X_{i j t}$ represents an individual's demographic, socioeconomic status, health behavior, and city-level climate variables in the living area. To be more specific, the demographic variables included whether male or female, marital status [reference group: married with spouse present (common-law marriage was considered married)], and age; socioeconomic status was measured by 
household income per capita, education level, employment status, insurance status, and rural/urban residence; educational attainment was defined at four levels (informal education, informal education but can read and write, primary school, and junior high school and above), and a categorical variable for educational attainment with four values was constructed, with informal education serving as the reference group; household income was divided by the number of household members and household income per capita was subsequently ranked and divided into five pentiles, with the lowest group serving as a reference; employment status was categorized into three groups: unemployed (including retired), self-employed, and wage earner; for health insurance coverage, respondents were recoded into a dummy variable with three values [the urban employee-based basic medical insurance scheme (UEBMI), the rural new cooperative medical scheme (NCMS), and the urban residentbased basic medical insurance scheme (URBMI)], with uninsured respondents as the reference group; current smoker and drinker were included as indicators of the respondents' current health behaviors; and city-level average monthly temperature, relative humidity, and city dummy variables were also controlled.

The interaction between chronic disease and air pollution intensity was then controlled in multivariate regression to establish whether chronic disease influences an individual's susceptibility to depressive symptoms with respect to air pollution,

$$
\begin{aligned}
\text { Depressive }_{i j t}= & b_{0}+\text { Air }_{j t} b_{1}+\text { Chronic }_{i j t} b_{2}+\text { Air }_{j t} \\
& \times \text { Chronic }_{i j t} b_{3}+X_{i j t} b_{4}+u_{i}+v_{t}+e_{i j t},
\end{aligned}
$$

where $b_{0}, b_{1}, b_{2}, b_{3}, b_{4}$ are the parameters to be estimated; Chronic $i_{i j t}$ is a dummy variable indicating whether a respondent has a chronic disease; and $A_{i r} \times$ Chronic $_{i j t}$ is the interaction between chronic disease and air pollution intensity after decentralization. Decentralization of air pollution indicators was calculated by subtracting the mean of city-level air pollution intensity from air pollution intensity in each city and then dividing it by the standard deviation of city-level air pollution intensity using the center-command in Stata 14 [48].

Analyses were then stratified according to chronic disease characteristics. Depressive symptoms may also affect an individual's physical health status and lead to endogenous issues [49]. Stratification was conducted to eliminate any possible endogenous issues by excluding respondents with chronic diseases (hypertension, dyslipidemia, diabetes or high blood sugar, cardiovascular diseases, arthritis and asthma) because such diseases may stem from depressive symptoms. Under these conditions no other possible methods were available for now.
The total CES-D scale used to evaluate depressive symptoms of middle-aged and elderly individuals ranged between 7 and 28, which represents a limited dependent variable. Therefore, least square regression was directly applied to render inconsistent estimates [50, 51]. The Tobit model was used for robust analysis in this respect, and marginal effects were reported,

$$
\begin{aligned}
\text { Depressive }_{i j t}^{*}= & c_{0}+\text { Air }_{j t} c_{1}+\text { Chronic }_{i j t} c_{2}+\text { Air }_{j t} \\
& \times \text { Chronic }_{i j t} c_{3}+X_{i j t} c_{4}+u_{i}+v_{t}+e_{i j t},
\end{aligned}
$$

$$
\text { Depressive }_{i j t}=7 \text { if Depressive } \text { ijt }^{*} \leq 7 \text {, }
$$

$$
\text { Depressive }_{i j t}=\text { Depressive }_{i j t}^{*} \quad \text { if } 7<\text { Depressive }_{i j t}^{*}<28,
$$

$$
\text { Depressive }_{i j t}=28 \text { if Depressive } \text { ijt }^{*} \geq 28,
$$

where $c_{0}, c_{1}, c_{2}, c_{3}, c_{4}$ are the parameters to be estimated; Depressive $_{i j t}^{*}$ is a latent variable and Depressive $e_{i j t}$ is its observable variable. A robust standard error was derived using bootstrapping methods and conducting 500 bootstrap replications.

In addition, by using the Tobit model with stratified samples, the effects of $\mathrm{SO}_{2}$ and TSP emission per capita/ per unit area on depression were regressed (and are presented in Appendix: Table 4). The results were consistent with those using air pollution emission intensity. Stata version 14 was used for all analyses [48].

\section{Results}

Participant characteristics and average air pollutant intensity across chronic disease are shown in Table 1. On average, $\mathrm{SO}_{2}$ and TSP emissions accounted for $82.950(\mathrm{SD}=78.355)$ and $45.571(\mathrm{SD}=49.025)$ tons per 100 million Chinese yuan of industrial GDP, respectively. $\mathrm{SO}_{2}$ emissions per unit area and per capita were $6.812(\mathrm{SD}=8.307)$ tons $/ \mathrm{km}^{2}$ and $135.137(\mathrm{SD}=120.211)$ tons/10,000 people; and TSP emissions per unit area and per capita were $3.079(\mathrm{SD}=3.495)$ tons $/ \mathrm{km}^{2}$ and 70.938 $(\mathrm{SD}=81.064)$ tons/10,000 people; and average temperature and humidity were $26.599{ }^{\circ} \mathrm{C}(\mathrm{SD}=3.935)$ and $73.253 \%(\mathrm{SD}=7.603)$, respectively.

The mean age of respondents was $60(\mathrm{SD}=9.989)$ years; $48 \%$ of respondents $(11,108 / 23,268)$ were male; $88 \%(20,414 / 23,268)$ were married or cohabiting; 39\% (9016/23,268) lived in an urban area; $44 \%$ $(10,191 / 23,268)$ of respondents had no formal education; $33 \%(7734 / 23,268)$ were unemployed; $44 \%$ $(10,162 / 23,268)$ were self-employed; and the majority had health insurance $[94 \%(21,813 / 23,268)]$. A total of $33 \%(7713 / 23,268)$ reported smoking and $33 \%(7756 / 23,268)$ reported drinking alcohol. The 
Table 1 Statistical description

\begin{tabular}{|c|c|c|c|c|c|c|c|}
\hline \multirow[t]{2}{*}{ Variable } & \multicolumn{2}{|c|}{$\begin{array}{l}\text { All sample } \\
(N=23,268)\end{array}$} & \multicolumn{2}{|c|}{$\begin{array}{l}\text { Group with chronic } \\
\text { disease }(N=15,412)\end{array}$} & \multicolumn{2}{|c|}{$\begin{array}{l}\text { Group } \\
\text { without chronic } \\
\text { disease }(\mathrm{N}=7856) \\
\end{array}$} & \multirow{2}{*}{$\begin{array}{l}\text { Group with chronic } \\
\text { disease VS Group } \\
\text { without chronic disease } \\
\text { P-value }^{\text {a }}\end{array}$} \\
\hline & Mean & Std. Dev. & Mean & Std. Dev. & Mean & Std. Dev. & \\
\hline \multicolumn{8}{|c|}{ Air pollution emission intensity (tons per 100 million Chinese yuan) } \\
\hline $\mathrm{SO}_{2}$ & 82.950 & 78.355 & 82.602 & 74.980 & 83.632 & 84.587 & $<0.001$ \\
\hline TSP & 45.571 & 49.025 & 46.510 & 50.816 & 43.729 & 45.253 & $<0.001$ \\
\hline \multicolumn{8}{|c|}{ Air pollution emission per unit area (tons $/ \mathrm{km}^{2}$ ) } \\
\hline $\mathrm{SO}_{2}$ & 6.812 & 8.307 & 6.667 & 8.728 & 7.097 & 7.403 & $<0.001$ \\
\hline TSP & 3.079 & 3.495 & 2.998 & 3.576 & 3.236 & 3.326 & $<0.001$ \\
\hline \multicolumn{8}{|c|}{ Air pollution emission per capita (tons/10,000 people) } \\
\hline $\mathrm{SO}_{2}$ & 135.137 & 120.211 & 132.127 & 118.256 & 141.042 & 123.753 & $<0.001$ \\
\hline TSP & 70.938 & 81.064 & 70.173 & 80.964 & 72.440 & 81.243 & $<0.001$ \\
\hline \multicolumn{8}{|l|}{ Climatic indexes } \\
\hline Average monthly temperature $\left(0.1^{\circ} \mathrm{C}\right)$ & 265.990 & 39.353 & 266.038 & 39.678 & 265.894 & 38.710 & $<0.001$ \\
\hline Average monthly relative humidity (\%) & 73.253 & 7.603 & 73.077 & 7.634 & 73.599 & 7.529 & $<0.001$ \\
\hline Depressive symptoms & 11.623 & 4.664 & 12.176 & 4.858 & 10.538 & 4.043 & $<0.001$ \\
\hline Age & 60.101 & 9.989 & 61.101 & 9.834 & 58.139 & 10.000 & $<0.001$ \\
\hline \multirow[t]{2}{*}{ Income (Chinese yuan/year) } & 8175 & 14,912 & 7970 & 13,343 & 8576 & 17,583 & 0.011 \\
\hline & $\mathrm{n}$ & $\%$ & $\mathrm{n}$ & $\%$ & $\mathrm{n}$ & $\%$ & $P_{\text {-value }}{ }^{b}$ \\
\hline Male & 11,108 & 47.739 & 7165 & 46.490 & 3943 & 50.191 & 0.010 \\
\hline Unmarried & 2854 & 12.266 & 1991 & 12.919 & 863 & 10.985 & 0.022 \\
\hline Living in urban area & 9016 & 38.748 & 5947 & 38.587 & 3069 & 39.066 & 0.730 \\
\hline Education & & & & & & & $<0.001$ \\
\hline No education & 5973 & 25.670 & 4145 & 26.895 & 1828 & 23.269 & \\
\hline No education but can read/write & 4218 & 18.128 & 2946 & 19.115 & 1272 & 16.191 & \\
\hline Primary school & 5181 & 22.267 & 3498 & 22.696 & 1683 & 21.423 & \\
\hline Junior high school and above & 7896 & 33.935 & 4823 & 31.294 & 3073 & 39.117 & \\
\hline Employment status & & & & & & & $<0.001$ \\
\hline Unemployed & 7734 & 33.239 & 5623 & 36.485 & 2111 & 26.871 & \\
\hline Self-employed & 10,162 & 43.674 & 6710 & 43.537 & 3452 & 43.941 & \\
\hline Wage earner & 5372 & 23.087 & 3079 & 19.978 & 2293 & 29.188 & \\
\hline Insurance & & & & & & & 0.037 \\
\hline Uninsured & 1455 & 6.253 & 854 & 5.541 & 601 & 7.650 & \\
\hline NCMS and URBMI & 18,635 & 80.089 & 12,389 & 80.385 & 6246 & 79.506 & \\
\hline UEBMI & 3178 & 13.658 & 2169 & 14.074 & 1009 & 12.844 & \\
\hline \multicolumn{8}{|l|}{ Health behavior } \\
\hline Current Smoker & 7713 & 33.149 & 4757 & 30.866 & 2956 & 37.627 & $<0.001$ \\
\hline Current Drinker & 7756 & 33.333 & 4932 & 32.001 & 2824 & 35.947 & 0.005 \\
\hline
\end{tabular}

a Frequencies with percentages were presented for categorical variables. P-values were calculated by Chi square test between groups having chronic disease or not b Means with standard deviations were presented for continuous variables, and P-values were calculated one-way ANOVA between groups having chronic disease or not

respondents earned an average of $8175(\mathrm{SD}=14,912)$ Chinese yuan per year per capita. The average depressive symptoms score was $11.623(\mathrm{SD}=4.664)$. Compared to participants with chronic disease, those without chronic disease were more likely to report lower depressive symptoms [12.176 $(\mathrm{SD}=4.858)$ versus $10.538(\mathrm{SD}=4.043)]$ but not more likely to be exposed to air pollution.
Models 1 and 3 from Table 2 show the correlation between air pollution and depressive symptoms in China after adjusting for multiple covariates. Increasing levels of air pollution were found to be significantly associated with higher depressive symptoms: an increase in $\mathrm{SO}_{2}$ and TSP emission intensities of $1 \%$ was associated with increasing depressive symptoms scores by 1.266 $(\mathrm{SE}=0.107, \mathrm{P}<0.001,95 \% \mathrm{CI} 1.057-1.475)$ and 1.318 
Table 2 Association of air pollution intensity and depressive symptoms and the role of chronic disease $(\mathrm{N}=\mathbf{2 3}, 268)$

\begin{tabular}{|c|c|c|c|c|c|c|c|c|}
\hline \multirow[t]{3}{*}{ Variables } & \multicolumn{4}{|c|}{$\begin{array}{l}\text { Influence of } \mathrm{SO}_{2} \text { emission intensity on depressive } \\
\text { symptoms }\end{array}$} & \multicolumn{4}{|c|}{$\begin{array}{l}\text { Influence of TSP emission intensity } \\
\text { on depressive symptoms }\end{array}$} \\
\hline & \multicolumn{2}{|l|}{ Model 1} & \multicolumn{2}{|l|}{ Model 2} & \multicolumn{2}{|l|}{ Model 3} & \multicolumn{2}{|l|}{ Model 4} \\
\hline & Coef. & Std. Err. & Coef. & Std. Err. & Coef. & Std. Err. & Coef. & Std. Err. \\
\hline Log of $\mathrm{SO}_{2}$ intensity & $1.266^{* * *}$ & 0.107 & $1.093^{* * *}$ & 0.116 & - & - & - & - \\
\hline Log of TSP intensity & - & - & - & - & $1.318^{* * *}$ & 0.082 & $1.115^{* * *}$ & 0.092 \\
\hline Chronic disease & - & - & $1.384^{* * *}$ & 0.068 & - & - & $1.388^{* * *}$ & 0.068 \\
\hline Log of $\mathrm{SO}_{2}$ intensity $\times$ Chronic disease & - & - & $0.217^{* * *}$ & 0.084 & - & - & - & - \\
\hline Log of TSP intensity $\times$ Chronic disease & - & - & - & - & - & - & $0.281^{* * *}$ & 0.071 \\
\hline Log of average monthly temperature & $0.189^{* *}$ & 0.085 & $0.176^{* *}$ & 0.085 & $0.201^{* *}$ & 0.087 & $0.191^{* *}$ & 0.087 \\
\hline Log of average monthly relative humidity & $-0.690^{* *}$ & 0.333 & $-0.693^{* *}$ & 0.332 & -0.445 & 0.335 & -0.451 & 0.333 \\
\hline \multicolumn{9}{|l|}{ Age group } \\
\hline $50-59$ & $0.248^{* * *}$ & 0.090 & 0.134 & 0.089 & $0.263^{* * *}$ & 0.090 & $0.148^{*}$ & 0.089 \\
\hline $60-69$ & 0.148 & 0.105 & -0.057 & 0.104 & $0.174^{*}$ & 0.104 & -0.031 & 0.103 \\
\hline More than 70 & $-0.396^{* * *}$ & 0.131 & $-0.606^{* * *}$ & 0.130 & $-0.368^{* * *}$ & 0.131 & $-0.578^{* * *}$ & 0.130 \\
\hline Male & $1.270^{* * *}$ & 0.091 & $1.269^{* * *}$ & 0.090 & $1.282^{* * *}$ & 0.091 & $1.283^{* * *}$ & 0.090 \\
\hline Unmarried & $0.680^{* * *}$ & 0.121 & $0.701^{* * *}$ & 0.119 & $0.682^{* * *}$ & 0.121 & $0.701^{* * *}$ & 0.119 \\
\hline Living in urban area & $-0.400^{* * *}$ & 0.104 & $-0.398^{* * *}$ & 0.103 & $-0.395^{* * *}$ & 0.104 & $-0.387^{* * *}$ & 0.103 \\
\hline \multicolumn{9}{|l|}{ Education } \\
\hline No education but can read/write & $0.414^{* * *}$ & 0.118 & $0.373^{* * *}$ & 0.116 & $0.416^{* * *}$ & 0.118 & $0.376^{* * *}$ & 0.116 \\
\hline Primary school & -0.043 & 0.112 & -0.081 & 0.110 & -0.039 & 0.112 & -0.077 & 0.110 \\
\hline Junior high school and above & $-0.470^{* * *}$ & 0.114 & $-0.454^{* * *}$ & 0.112 & $-0.461^{* * *}$ & 0.114 & $-0.448^{* * *}$ & 0.112 \\
\hline \multicolumn{9}{|l|}{ Employment status } \\
\hline Self-employed & $-0.165^{*}$ & 0.089 & -0.109 & 0.088 & $-0.152^{*}$ & 0.088 & -0.096 & 0.088 \\
\hline Wage earner & $-0.351^{* * *}$ & 0.090 & $-0.262^{* * *}$ & 0.089 & $-0.354^{* * *}$ & 0.090 & $-0.265^{* * *}$ & 0.089 \\
\hline \multicolumn{9}{|l|}{ Insurance } \\
\hline NCMS and URBMI & -0.061 & 0.130 & -0.123 & 0.129 & -0.052 & 0.129 & -0.113 & 0.128 \\
\hline UEMBI & $-0.432^{* * *}$ & 0.152 & $-0.520^{* * *}$ & 0.151 & $-0.418^{* * *}$ & 0.151 & $-0.503^{* * *}$ & 0.150 \\
\hline \multicolumn{9}{|l|}{ Income group } \\
\hline 21-40th percentile & $0.328^{* * *}$ & 0.100 & $0.335^{* * *}$ & 0.099 & $0.340^{* * *}$ & 0.100 & $0.349^{* * *}$ & 0.099 \\
\hline 41-60th percentile & 0.078 & 0.096 & 0.068 & 0.095 & 0.091 & 0.096 & 0.082 & 0.095 \\
\hline 61-80th percentile & -0.073 & 0.096 & -0.068 & 0.095 & -0.063 & 0.096 & -0.056 & 0.095 \\
\hline 81-100th percentile & $-0.289^{* * *}$ & 0.101 & $-0.296^{* * *}$ & 0.100 & $-0.288^{* * *}$ & 0.101 & $-0.295^{* * *}$ & 0.100 \\
\hline \multicolumn{9}{|l|}{ Health behavior } \\
\hline Current drinker & 0.040 & 0.072 & 0.108 & 0.072 & 0.0459 & 0.072 & 0.114 & 0.072 \\
\hline Current smoker & $-0.196^{* *}$ & 0.081 & $-0.156^{*}$ & 0.080 & $-0.186^{* *}$ & 0.081 & $-0.144^{*}$ & 0.080 \\
\hline Constant & $7.165^{* * *}$ & 1.548 & $7.025^{* * *}$ & 1.562 & $7.219^{* * *}$ & 1.538 & $7.079^{* * *}$ & 1.544 \\
\hline City dummy variables & YES & & YES & & YES & & YES & \\
\hline Adjusted $R^{2}$ & 0.139 & & 0.165 & & 0.139 & & 0.165 & \\
\hline Wald Chi square & $2126^{* * *}$ & & $2596^{* * *}$ & & $2228^{* * *}$ & & $2707^{* * *}$ & \\
\hline
\end{tabular}

Models 1-4 are estimated using the xi:xtreg-command in Stata 14. Decentralization was calculated using the center-command ${ }^{*} \mathrm{P}<0.10$; ${ }^{* *} \mathrm{P}<0.05 ;{ }^{* * *} \mathrm{P}<0.01$

$(\mathrm{SE}=0.082, \quad \mathrm{P}<0.001,95 \%$ CI $1.157-1.480)$, respectively. Models 2 and 4 from Table 2 present the interaction between air pollution and chronic disease and their effect on depressive symptoms. After controlling for the interaction of air pollution and chronic disease, a positive correlation between air pollution and depressive symptoms was observed, as expected. An $1 \%$ increase in the intensities of $\mathrm{SO}_{2}$ and TSP emissions was associated with $1.237(1.093(\mathrm{SE}=0.116, \mathrm{P}<0.001,95 \% \mathrm{CI}$ $0.866-1.320)+0.217 \quad(\mathrm{SE}=0.084, \quad \mathrm{P}=0.009, \quad 95 \% \quad \mathrm{CI}$ $0.053-0.380) \times 15,412 / 23,268=1.093+0.217 \times 66 \%)$ and $1.301(1.115(\mathrm{SE}=0.092, \mathrm{P}<0.001,95 \% \mathrm{CI} 0.934-$ $1.296)+0.281 \quad(\mathrm{SE}=0.071, \quad \mathrm{P}<0.001, \quad 95 \%$ CI $0.143-$ $0.420) \times 66 \%$ ) higher depressive symptoms scores, 
respectively. In addition, due to an $1 \%$ increase in the intensities of $\mathrm{SO}_{2}$ and TSP emissions, the depressive symptoms scores for respondents with chronic disease increased by 1.903 (1.384 ( $\mathrm{SE}=0.068, \mathrm{P}<0.001,95 \%$ CI $1.250-1.518)+0.217(\mathrm{SE}=0.084, \mathrm{P}=0.009,95 \% \mathrm{CI}$ $0.053-0.380) \times \log (82.950))$ and $1.854(1.388(\mathrm{SE}=0.068$, $\mathrm{P}<0.001, \quad 95 \% \quad$ CI $1.254-1.522)+0.281 \quad$ (SE $=0.071$, $\mathrm{P}<0.001$, 95\% CI $0.143-0.420) \times \log (45.571)$ ), respectively. Given the same intensities of $\mathrm{SO}_{2}$ and TSP emissions, respondents with chronic disease had higher scores for depressive symptoms by 0.217 ( $\mathrm{SE}=0.084, \mathrm{P}=0.009$, 95\% CI $0.053-0.380)$ and $0.281(\mathrm{SE}=0.071, \mathrm{P}<0.001$, 95\% CI 0.143-0.420) than those without chronic disease.

Models 1-4 from Table 3 show the results stratified using chronic disease characteristics; models 5-8 show results using the Tobit model; models 9-12 show the results stratified using chronic disease characteristics and the Tobit model. Robust analysis shows that the results obtained were consistent with those using the random effects model. According to models 10 and 12 from Table 3, for individuals with cancer or malignant tumor, chronic lung diseases, liver diseases, kidney disease, and stomach diseases, when the $\mathrm{SO}_{2}$ and TSP emission intensities increased by $1 \%$ individuals showed an increase in depressive symptom scores of $0.844(0.788 \quad(\mathrm{SE}=0.128, \mathrm{P}<0.001,95 \%$ CI $0.537-$ $1.039)+0.221 \quad(\mathrm{SE}=0.091, \quad \mathrm{P}=0.015,95 \%$ CI $0.044-$ $0.399) \times 2669 / 10,508=(0.788+0.221 \times 25 \%)$ and 0.818 $(0.765(\mathrm{SE}=0.118, \mathrm{P}<0.001,95 \%$ CI $0.534-0.997)+0.208$ $(\mathrm{SE}=0.107, \mathrm{P}=0.051,95 \%$ CI $0-0.417) \times 25 \%)$, respectively. In addition, due to an $1 \%$ increase in the intensities of $\mathrm{SO}_{2}$ and TSP emissions, respondents with these chronic diseases scored higher for depressive symptoms by $1.292(0.869 \quad(\mathrm{SE}=0.102, \quad \mathrm{P}<0.001,95 \% \mathrm{CI}$ $0.668-1.069)+0.221 \quad(\mathrm{SE}=0.091, \quad \mathrm{P}=0.015, \quad 95 \% \quad \mathrm{CI}$ $0.044-0.399) \times \log (82.000))$ and $1.208(0.866(\mathrm{SE}=0.114$, $\mathrm{P}<0.001, \quad 95 \% \quad \mathrm{CI} \quad 0.643-1.090)+0.208 \quad(\mathrm{SE}=0.107$, $\mathrm{P}=0.051,95 \%$ CI $0-0.417) \times \log (43.885)$ ), respectively. Given the same intensities of $\mathrm{SO}_{2}$ and TSP emissions, individuals with chronic disease had higher scores for depressive symptoms by 0.221 ( $\mathrm{SE}=0.091, \mathrm{P}=0.015,95 \%$ CI 0.044-0.399) and $0.208(\mathrm{SE}=0.107, \mathrm{P}=0.051,95 \% \mathrm{CI}$ $0-0.417)$ than those without chronic disease. However, the impacts of air pollution were reduced after eliminating the endogenous variable, which supports the hypothesis that depressive symptoms influence physical health.

\section{Discussion}

To the best of the authors' knowledge, this is the first published article to elucidate the role of chronic disease in an association between air pollution and depressive symptoms within the Chinese population, who prefer to acknowledge poor mental conditions instead of mental illness. Using nationally representative data for the general Chinese middle- and old-aged population, this study found that exposure to air pollution was related to depression and that if an individual had a chronic disease, they were more vulnerable to the depressive symptoms effects of air pollution. These findings provide a comprehensive understanding of the extent that air pollution affects depression, which could provide valuable insights for the design of policies and promotional programs to enhance the quality of mental health and curb the negative effects of air pollution in China.

The results of a positive association between air pollution and depression are consistent with those of previous Chinese studies and results from Japan, Korea, Canada, and the Netherlands [8,13-17], but are contradictory to results from Norway and Boston [27, 52]. This discrepancy could possibly be related to the intensity of air pollution $[52,53]$. For example, air pollution in China occurs at some of the highest levels in the world: in Yale University's 2016 Environmental Performance Index, China is ranked 109 out of 180 countries [54]. Therefore, insignificant results from countries with low pollution levels merely indicate that a minor amount of air pollution is not harmful with respect to depression, whereas levels are high in China, are causing health issues, and are continuing to rise.

This study also identifies susceptible subgroups and extends research on the subject of adverse mental health effects relating to air pollution by testing the assumption that individuals with chronic disease were more vulnerable to depressive symptoms effects relating to air pollution. It is of note that our study found that individuals with cardiovascular disease were more likely to report depressive symptoms related to air pollution compared to those without chronic disease, even when results were adjusted for other factors. While no studies have investigated the role of air pollution and depression relating to chronic disease, the relationship determined here is consistent with results of studies showing a relationship between (1) exposure to ambient air pollution and an increase in chronic mortality and morbidity [55-65]; (2) chronic disease and depressive symptoms [66].

Considering the large variation in optimal thresholds for identifying depressive symptoms in self-reported responses, this study adopted a continuous variable to measure depressive symptoms, instead of using a cut-off point to dichotomously distinguish depressive symptoms [67]. In doing so, caution is also warranted when attaching pathological labels to self-reported symptoms [68]. A dimensional scale with higher scores indicating more symptoms provides enhanced clarification of depressive symptoms [69], particularly for individuals with a Chinese cultural background where depressive symptoms are highly stigmatized $[55,70]$. 
Table 3 Association of air pollution intensity and depressive symptoms and the role of chronic disease: Robustness test

\begin{tabular}{|c|c|c|c|c|c|c|c|c|}
\hline \multirow[t]{3}{*}{ Variables } & \multicolumn{4}{|c|}{ Influence of $\mathrm{SO}_{2}$ emission intensity on depressive symptoms } & \multicolumn{4}{|c|}{$\begin{array}{l}\text { Influence of TSP emission intensity on depressive } \\
\text { symptoms }\end{array}$} \\
\hline & \multicolumn{2}{|l|}{ Model 1} & \multicolumn{2}{|l|}{ Model 2} & \multicolumn{2}{|l|}{ Model 3} & \multicolumn{2}{|l|}{ Model 4} \\
\hline & Coef. & Std. Err. & Coef. & Std. Err. & Coef. & Std. Err. & Coef. & Std. Err. \\
\hline \multicolumn{9}{|c|}{$\begin{array}{l}\text { Association of air pollution intensity and depressive symptoms and the role of chronic disease among respondents without mental-related chronic disease } \\
(N=10,508)\end{array}$} \\
\hline Log of $\mathrm{SO}_{2}$ intensity & $0.952^{* * *}$ & 0.141 & $0.901^{* * *}$ & 0.145 & - & - & - & - \\
\hline Log of TSP intensity & - & - & - & - & $0.929^{* * *}$ & 0.115 & $0.875^{* * *}$ & 0.118 \\
\hline Chronic disease & - & - & $0.993^{* * *}$ & 0.113 & - & - & $0.991^{* * *}$ & 0.113 \\
\hline $\begin{array}{l}\text { Log of } \mathrm{SO}_{2} \text { inten- } \\
\text { sity } \times \text { chronic disease }\end{array}$ & - & - & $0.256^{*}$ & 0.138 & - & - & - & - \\
\hline $\begin{array}{l}\text { Log of TSP inten- } \\
\text { sity } \times \text { chronic disease }\end{array}$ & - & - & - & - & - & - & $0.240^{* *}$ & 0.118 \\
\hline Adjusted $R^{2}$ & 0.123 & & 0.139 & & 0.123 & & 0.140 & \\
\hline \multirow[t]{3}{*}{ Wald Chi square } & $862^{* * *}$ & & $961^{* * *}$ & & $876^{* * *}$ & & $974^{* * *}$ & \\
\hline & \multicolumn{2}{|l|}{ Model 5} & \multicolumn{2}{|l|}{ Model 6} & \multicolumn{2}{|l|}{ Model 7} & \multicolumn{2}{|l|}{ Model 8} \\
\hline & Marginal effects & Boot. Std. & Marginal effects & Boot. Std. & Marginal effects & Boot. Std. & Marginal effects & Boot. Std. \\
\hline \multicolumn{9}{|c|}{ Association of air pollution intensity and depressive symptoms and the role of chronic disease: Tobit model $(N=23,268)$} \\
\hline Log of $\mathrm{SO}_{2}$ intensity & $1.122^{* * *}$ & 0.101 & $0.969^{* * *}$ & 0.090 & - & - & - & - \\
\hline Log of TSP intensity & - & - & - & - & $1.169^{* * *}$ & 0.071 & $0.989^{* * *}$ & 0.068 \\
\hline Chronic disease & - & - & $1.227^{* * *}$ & 0.056 & - & - & $1.230^{* * *}$ & 0.065 \\
\hline $\begin{array}{l}\text { Log of } \mathrm{SO}_{2} \text { inten- } \\
\text { sity } \times \text { chronic disease }\end{array}$ & - & - & $0.191^{* * *}$ & 0.063 & - & - & - & - \\
\hline $\begin{array}{l}\text { Log of TSP inten- } \\
\text { sity } \times \text { chronic disease }\end{array}$ & - & - & - & - & - & - & $0.248^{* * *}$ & 0.061 \\
\hline Sigma(u) & $2.484^{* * *}$ & 0.054 & $2.406^{* * *}$ & 0.038 & $2.491^{* * *}$ & 0.042 & $2.414^{* * *}$ & 0.040 \\
\hline Sigma(e) & $3.663^{* * *}$ & 0.029 & $3.661^{* * *}$ & 0.024 & $3.653^{* * *}$ & 0.037 & $3.650^{* * *}$ & 0.030 \\
\hline \multirow[t]{3}{*}{ Log likelihood } & \multicolumn{2}{|l|}{$-67,019$} & \multicolumn{2}{|l|}{$-66,835$} & \multicolumn{2}{|l|}{$-66,985$} & \multicolumn{2}{|l|}{$-66,798$} \\
\hline & \multicolumn{2}{|l|}{ Model 9} & \multicolumn{2}{|l|}{ Model 10} & \multicolumn{2}{|l|}{ Model 11} & \multicolumn{2}{|l|}{ Model 12} \\
\hline & Marginal effects & Boot. Std. & Marginal effects & Boot. Std. & Marginal effects & Boot. Std. & Marginal effects & Boot. Std. \\
\hline \multicolumn{9}{|c|}{$\begin{array}{l}\text { Association of air pollution intensity and depressive symptoms and the role of chronic disease among respondents without mental-related chronic disease: } \\
\text { Tobit model }(N=10,508)\end{array}$} \\
\hline Log of $\mathrm{SO}_{2}$ intensity & $0.832^{* * *}$ & 0.122 & $0.788^{* * *}$ & 0.128 & - & - & - & - \\
\hline Log of TSP intensity & - & - & - & - & $0.812^{* * *}$ & 0.102 & $0.765^{* * *}$ & 0.118 \\
\hline Chronic disease & - & - & $0.869^{* * *}$ & 0.102 & - & - & $0.866^{* * *}$ & 0.114 \\
\hline $\begin{array}{l}\text { Log of } \mathrm{SO}_{2} \text { inten- } \\
\text { sity } \times \text { chronic disease }\end{array}$ & - & - & $0.221^{* *}$ & 0.091 & - & - & - & - \\
\hline $\begin{array}{l}\text { Log of TSP inten- } \\
\text { sity } \times \text { chronic disease }\end{array}$ & - & - & - & - & - & - & $0.208^{* *}$ & 0.107 \\
\hline Sigma(u) & $2.098^{* * *}$ & 0.068 & $2.052^{* * *}$ & 0.064 & $2.103^{* * *}$ & 0.071 & $2.056^{* * *}$ & 0.070 \\
\hline Sigma(e) & $3.440^{* * *}$ & 0.042 & $3.441^{* * *}$ & 0.050 & $3.434^{* * *}$ & 0.038 & $3.435^{* * *}$ & 0.048 \\
\hline Log likelihood & $-29,353$ & & $-29,307$ & & $-29,344$ & & $-29,297$ & \\
\hline
\end{tabular}

Models 1-4 are estimated using the xi:xtreg-command in Stata 14, models 5-12 are estimated using the xi:xttobit-command. Decentralization was calculated using the center-command, and Marginal effects was calculated using the margins-command

Control variables included individual's demographic, socioeconomic status, health behaviors and city-level climate variables in living areas. City dummy variables were also controlled

${ }^{*} \mathrm{P}<0.10$; ** $\mathrm{P}<0.05$; *** $\mathrm{P}<0.01$

Nevertheless, the limitations of this study should be considered before discussing potential policy implications. The previous studies proved that other contaminants such as $\mathrm{PM}_{10}$ or $\mathrm{PM}_{2.5}$ may also be related to mental health effects
[52]. However, use of these air pollution compounds was restricted in our analysis due to data constraints. A further limitation relating to data constraints is that only annual air pollution intensity data were available for use, which 
cannot be fully correlated with weekly depression symptoms. Although such data and associated results are useful in that depressive symptoms may result from accumulated exposure to air pollution [53], it is not possible to untangle short-term effects from long-term effects in this study. However, although caution should be taken when explaining the results, it is clear that high levels of $\mathrm{SO}_{2}$ and TSP within lead to depression.

An underlying endogeneity problem may exist if depressive symptoms also affect an individual's chronic disease status, which would lead to a simultaneity issue [49, 71, 72]. For example, a depressed patient could become trapped in a negative cycle in which mental symptoms are exacerbated by the synergistic effect of stress and cardiovascular risk factors, or where a patient is vulnerable to acute cardiovascular events due to the synergistic effect of mental stress and an underlying atherothrombotic disorder [72]. It is considered that depressive symptoms can have an influence on the occurrence of hypertension, dyslipidemia, diabetes or high blood sugar, cardiovascular diseases, arthritis and asthma [71-83]. However, our individual level data relied on retrospective self-evaluation, which is potentially endogenous due to measurement errors. Although quasiexperimental or instrument variables could have corrected the bias [84] these corrections are now unavailable because of data limitations. The analyses presented here focused on a subsample of the population that excluded respondents suffering from chronic diseases stemming from depressive symptoms. To be specific, respondents with hypertension, dyslipidemia, diabetes or high blood sugar, cardiovascular diseases, arthritis and asthma were not included in subsample analysis [71-83]. As expected, our results show that compared to those without chronic disease, individuals with chronic disease not directly related to mental health were more likely to suffer from depression. Therefore, even when chronic disease is not considered to be a direct cause of depression in China, chronic disease influences an individual's susceptibility to air pollution triggering depressive symptoms.

Given the above limitations, it is considered the results of this study can be used when establishing air pollution policies and policies related to both individual and public health concerns. In this respect, the adverse effects of air pollution on mental health should firstly be considered when establishing air pollution guidelines. If the unfavorable impacts of air pollution on mental health are overlooked, the national emission standard levels may be higher than optimal, which could result in excessive amounts of air pollutants being emitted. In addition, our findings provide a justification for establishing mental health interventions that target air pollution exposure. Public health policies should provide vulnerable people with information to help them cope with the adverse effects of air pollution. Furthermore, respondents with chronic disease found that depressive symptoms were particularly susceptible to fluctuations in air quality. Although all individuals are potentially exposed to ambient pollution, the evidence suggests that being of sound physical health cushions the depressive symptom effects of air pollution exposure. As such, basing policies on effects observed in the general population may be insufficient to protect vulnerable subgroups. The Chinese government needs to enhance and focus prevention strategies for those with chronic disease. For example, the Air Quality Health Index could provide different public advice for those with an elevated risk due to chronic disease when providing a summary of the air quality and advice to prevent adverse health effects [85].

\section{Conclusion}

This study evaluated the association between air pollution and depressive symptoms and was based on nationally representative data relating to the Chinese middle- and old-aged population. The role of chronic disease with respect to air pollution and depressive symptoms was also estimated. Air pollution was found to be an important determinant of depressive symptoms, particularly for those with chronic disease. When an individual had a chronic disease, they were more vulnerable to the depressive symptoms effects of air pollution than those without chronic disease. Therefore, the adverse health effects of air pollution should be taken into consideration while establishing environmental and public health policies.

\section{Abbreviations \\ ANOVA: Analysis of Variance; CES-D: Center for Epidemiologic Studies Depres- sion; CHARLS: China Health and Retirement Longitudinal Study; GDP: gross domestic product; NCMS: the rural new cooperative medical scheme; $\mathrm{NO}_{2}$ nitrogen dioxide; $\mathrm{PM}_{10}$ : particle size smaller than $10 \mu \mathrm{m} ; \mathrm{PM}_{25}$ : particle size smaller than $2.5 \mu \mathrm{m} ; \mathrm{SO}_{2}$ : sulfur dioxide; TSP: total suspended particulates (particle size smaller than $100 \mu \mathrm{m}$ ); UEBMI: the urban employee-based basic medical insurance scheme; URBMI: the urban resident-based basic medical insurance scheme; WHO: World Health Organization.}

\section{Authors' contributions}

QW, ZY conceived the paper. QW wrote the paper, ZY analyzed and interpreted the data. Both authors read and approved the final manuscript.

\section{Author details \\ ${ }^{1}$ School of Business, Dalian University of Technology, Panjin 124221, Liaoning, China. ${ }^{2}$ Donlinks School of Economics and Management, University of Sci- ence and Technology Beijing, Beijing 100083, China.}

\section{Acknowledgements}

We would like to acknowledge the China Health and Retirement Longitudinal Study team for providing data and the training of using the dataset.

Competing interests

The authors declare that they have no competing interests. 


\section{Consent for publication}

All of the authors have read and approved the paper and it has not been published previously nor is it being considered by any other peer-reviewed journal.

Ethics approval and consent to participate

The study was approved by the Institutional Review Board of Peking University with ethical approval NO. (IRB00001052-11014).

\section{Funding}

This paper was supported by the National Natural Science Foundation of China (Nos. 71503059; 71673022; 71420107023); the Fundamental Research
Funds for the Central Universities [Nos. FRF-TP-16-050A1; FRF-BR-17-005B; DUT17RC(4)24]; Dalian Social Science Foundation (No. 2016dlskyb004); Beijing Social Science Foundation (No. 17LJB004).

\section{Table 4 Association of air pollution emission per capita/per unit area and depressive symptoms and the role of chronic} disease: Robustness test

\begin{tabular}{|c|c|c|c|c|c|c|c|c|}
\hline \multirow[t]{3}{*}{ Variables } & \multicolumn{4}{|c|}{$\begin{array}{l}\text { Influence of } \mathrm{SO}_{2} \text { emission intensity on depressive } \\
\text { symptoms }\end{array}$} & \multicolumn{4}{|c|}{$\begin{array}{l}\text { Influence of TSP emission intensity on depressive } \\
\text { symptoms }\end{array}$} \\
\hline & \multicolumn{2}{|l|}{ Model 1} & \multicolumn{2}{|l|}{ Model 2} & \multicolumn{2}{|l|}{ Model 3} & \multicolumn{2}{|l|}{ Model 4} \\
\hline & Marginal effects & Boot. Std. & Marginal effects & Boot. Std. & Marginal effects & Boot. Std. & Marginal effects & Boot. Std. \\
\hline \multicolumn{9}{|c|}{$\begin{array}{l}\text { Association of air pollution emission per unit area (tons per square kilometer) and depressive symptoms and the role of chronic disease among } \\
\text { respondents without mental-related chronic disease: Tobit model }(N=10,508)\end{array}$} \\
\hline $\begin{array}{l}\text { Log of } \mathrm{SO}_{2} \text { emission } \\
\text { per unit area }\end{array}$ & 0.191 & 0.163 & 0.156 & 0.153 & - & - & - & - \\
\hline $\begin{array}{l}\text { Log of TSP emission } \\
\text { per unit area }\end{array}$ & - & - & - & - & $0.490^{* * *}$ & 0.132 & $0.419^{* * *}$ & 0.161 \\
\hline Chronic disease & - & - & $0.856^{* * *}$ & 0.107 & - & - & $0.861^{* * *}$ & 0.094 \\
\hline $\begin{array}{l}\text { Log of } \mathrm{SO}_{2} \text { emis- } \\
\text { sion per unit } \\
\text { area } \times \text { chronic } \\
\text { disease }\end{array}$ & - & - & $0.161^{*}$ & 0.093 & - & - & - & - \\
\hline $\begin{array}{l}\text { Log of TSP emis- } \\
\text { sion per unit } \\
\text { area } \times \text { chronic } \\
\text { disease }\end{array}$ & - & - & - & - & - & - & $0.284^{* *}$ & 0.124 \\
\hline $\operatorname{Sigma}(\mathrm{u})$ & $2.088^{* * *}$ & 0.063 & $2.040^{* * *}$ & 0.079 & $2.092^{* * *}$ & 0.057 & $2.043^{* * *}$ & 0.072 \\
\hline Sigma(e) & $3.453^{* * *}$ & 0.042 & $3.456^{* * *}$ & 0.040 & $3.449^{* * *}$ & 0.037 & $3.451^{* * *}$ & 0.040 \\
\hline \multirow[t]{3}{*}{ Log likelihood } & $-29,375$ & & $-29,329$ & & $-29,368$ & & $-29,320$ & \\
\hline & \multicolumn{2}{|l|}{ Model 5} & \multicolumn{2}{|l|}{ Model 6} & \multicolumn{2}{|l|}{ Model 7} & \multicolumn{2}{|l|}{ Model 8} \\
\hline & Marginal effects & Boot. Std. & Marginal effects & Boot. Std. & Marginal effects & Boot. Std. & Marginal effects & Boot. $S$ \\
\hline
\end{tabular}

Association of air pollution emission per capita (tons per 10 thousand people) and depressive symptoms and the role of chronic disease among respondents without mental-related chronic disease: Tobit model $(\mathrm{N}=10,508)$

\begin{tabular}{|c|c|c|c|c|c|c|c|c|}
\hline $\begin{array}{l}\text { Log of } \mathrm{SO}_{2} \text { emission } \\
\text { per capita }\end{array}$ & $0.359^{* * *}$ & 0.122 & $0.332^{* *}$ & 0.137 & - & - & - & - \\
\hline $\begin{array}{l}\text { Log of TSP emission } \\
\text { per capita }\end{array}$ & - & - & - & - & $0.615^{* * *}$ & 0.121 & $0.564^{* * *}$ & 0.122 \\
\hline Chronic disease & - & - & $0.860^{* * *}$ & 0.114 & - & - & $0.865^{* * *}$ & 0.088 \\
\hline $\begin{array}{l}\text { Log of } \mathrm{SO}_{2} \text { emission } \\
\text { per capita } \times \text { chronic } \\
\text { disease }\end{array}$ & - & - & 0.145 & 0.105 & - & - & - & - \\
\hline $\begin{array}{l}\text { Log of TSP emission } \\
\text { per capita } \times \text { chronic } \\
\text { disease }\end{array}$ & - & - & - & - & - & - & $0.211^{*}$ & 0.118 \\
\hline Sigma(u) & $2.089^{* * *}$ & 0.072 & $2.041^{* * *}$ & 0.057 & $2.093^{* * *}$ & 0.081 & $2.046^{* * *}$ & 0.076 \\
\hline Sigma(e) & $3.452^{* * *}$ & 0.041 & $3.455^{* * *}$ & 0.034 & $3.447^{* * *}$ & 0.048 & $3.449^{* * *}$ & 0.037 \\
\hline Log likelihood & $-29,374$ & & $-29,329$ & & $-29,365$ & & $-29,319$ & \\
\hline
\end{tabular}

Models 1-8 are estimated using the xi:xttobit-command in Stata 14. Decentralization was calculated using the center-command, and Marginal effects was calculated using the margins-command

Control variables included individual's demographic, socioeconomic status, health behaviors and city-level climate variables in living areas. City dummy variables were also controlled

*P $\mathrm{P} 0.10$; * $\mathrm{P}<0.05$; ** $\mathrm{P}<0.01$ 


\section{Publisher's Note}

Springer Nature remains neutral with regard to jurisdictional claims in published maps and institutional affiliations.

Received: 20 December 2017 Accepted: 11 June 2018

Published online: 18 June 2018

\section{References}

1. Shi M, Ma G, Shi Y. How much real cost has China paid for its economic growth? Sustain Sci. 2011;6(2):135-49.

2. Foster KW. The River Runs Black: the environmental challenge to China's future. By Economy Elizabeth C. Ithaca, NY: Cornell University Press, 2004. p. 337 \$29.95 (Cloth). J East Asian Stud. 2005;5(3):512-23.

3. Li X, Song J, Lin T, Dixon J, Zhang G, Ye H. Urbanization and health in China, thinking at the national, local and individual levels. Environ Health. 2016;15(Suppl 1):23

4. Zhang XX, Shi PJ, Liu LY, Tang Y, Cao HW, Zhang XN, Hu X, Guo LL, Lue YL, Qu ZQ, Jia ZJ, Yang YY. Ambient TSP concentration and dustfall in major cities of China: spatial distribution and temporal variability. Atmos Environ. 2010;44(13):1641-8.

5. Baldasano JM, Valera E, Jimenez P. Air quality data from large cities. Sci Total Environ. 2003;307(1-3):141-65.

6. World Health Organization. Occupational and Environmental Health Team. Guidelines for air quality. Geneva: World Health Organization. 2000. http://www.who.int/iris/handle/10665/66537. Accessed 14 June 2018

7. Shah MH, Shaheen N. Annual TSP and trace metal distribution in the urban atmosphere of Islamabad in comparison with mega-cities of the world. Hum Ecol Risk Assess. 2007;13(4):884-99.

8. Lim YH, Kim H, Kim JH, Bae S, Park HY, Hong YC. Air pollution and symptoms of depression in elderly adults. Environ Health Perspect. 2012;120(7):1023-8.

9. Grippo AJ. Mechanisms underlying altered mood and cardiovascular dysfunction: the value of neurobiological and behavioral research with animal models. Neurosci Biobehav Rev. 2009:33(2):171-80.

10. Block ML, Wu X, Pei Z, Li G, Wang T, Qin L, Wilson B, Yang J, Hong JS, Veronesi B. Nanometer size diesel exhaust particles are selectively toxic to dopaminergic neurons: the role of microglia, phagocytosis, and NADPH oxidase. Faseb J. 2004;18(13):1618-20.

11. Campbell A, Oldham M, Becaria A, Bondy SC, Meacher D, Sioutas C, Misra C, Mendez LB, Kleinman M. Particulate matter in polluted air may increase biomarkers of inflammation in mouse brain. Neurotoxicology. 2005;26(1):133-40.

12. Veronesi B, Makwana O, Pooler M, Chen LC. Effects of subchronic exposures to concentrated ambient particles. VII. Degeneration of dopaminergic neurons in Apo E-/- mice. Inhal Toxicol. 2005;17(4-5):235-41.

13. Yamazaki S, Nitta H, Fukuhara S. Associations between exposure to ambient photochemical oxidants and the vitality or mental health domain of the health related quality of life. J Epidemiol Commun $\mathrm{H}$. 2006:60(2):173-9.

14. Yamazaki S, Nitta H, Murakami Y, Fukuhara S. Association between ambient air pollution and health-related quality of life in Japan: ecological study. Int J Environ Health Rew. 2015;15(5):383-91.

15. Boezen HM, Zee SCVD, Postma DS, Vonk JM, Gerritsen J, Hoek G, Brunekreef B, Rijcken B, Schouten JP. Effects of ambient air pollution on upper and lower respiratory symptoms and peak expiratory flow in children. Lancet. 1999:353(9156):874-8.

16. Szyszkowicz M, Rowe BH, Colman I. Air pollution and daily emergency department visits for depression. Int J Occup Med Environ Health. 2009;22(4):355-62.

17. Cho J, Choi YJ, Suh M, Sohn J, Kim H, Cho SK, Ha KH, Kim C, Shin DC. Air pollution as a risk factor for depressive episode in patients with cardiovascular disease, diabetes mellitus, or asthma. J Affect Disord. 2014;157:45-51.

18. Phillips MR, Yang G, Zhang $Y$, Wang $L$, Ji H, Zhou M. Risk factors for suicide in China: a national case-control psychological autopsy study. Lancet. 2002;360(9347):1728-36.
19. Zhao Y, Smith JP, Strauss J. Can China age healthily? Lancet. 2014;384(9945):723-4.

20. Charlson FJ, Baxter AJ, Cheng HG, Shidhaye R, Whiteford HA. The burden of mental, neurological, and substance use disorders in China and India: a systematic analysis of community representative epidemiological studies. Lancet. 2016;388(10042):376-89.

21. Zhang X, Zhang X, Chen X. Happiness in the air: how does a dirty sky affect mental health and subjective well-being? J Environ Econ Manag. 2017:85:81-94

22. Li Z, Folmer H, Xue J. To what extent does air pollution affect happiness? The case of the Jinchuan mining area, China. Ecol Econ. 2014;99:88-99.

23. Tian T, Chen Y, Zhu J, Liu P. Effect of air pollution and rural-urban difference on mental health of the elderly in China. Iran J Public Health. 2015:44(8):1084-94

24. Sun R, Gu D. Air pollution economic development of communities, and health status among the elderly in urban China. Am J Epidemiol. 2008;168(11):1311-8.

25. Zeng Y, Gu D, Purser J, Hoenig H, Christakis N. Associations of environmental factors with elderly health and mortality in China. Am J Public Health. 2010:100(2):298-305.

26. Gao Q, Xu Q, Guo X, Fan H, Zhu H. Particulate matter air pollution associated with hospital admissions for mental disorders: a time-series study in Beijing, China. Eur Psychiat. 2017;44:68-75

27. Wang Y, Eliot MN, Koutrakis P, Gryparis A, Schwartz JD, Coull BA, Mittleman MA, Milberg WP, Lipsitz LA, Wellenius GA. Ambient air pollution and depressive symptoms in older adults: results from the MOBILIZE Boston study. Environ Health Perspect. 2014:122(6):553-8.

28. Power MC, Kioumourtzoglou MA, Hart JE, Okereke OI, Laden F, Weisskopf MG. The relation between past exposure to fine particulate air pollution and prevalent anxiety: observational cohort study. Brit Med J. 2015:350(23):h1111.

29. Lamers F, van Oppen P, Comijs HC, Smit JH, Spinhoven P, van Balkom AJ, Nolen WA, Zitman FG, Beekman ATF, Penninx B. Comorbidity patterns of anxiety and depressive disorders in a large cohort study: the Netherlands Study of Depression and Anxiety (NESDA). J Clin Psychiat. 2011;72(3):341-8.

30. Tallon L, Pun VC, Manjourides J, Suh HH. Cognitive impacts of ambient air pollution in the National Social Health and Aging Project (NSHAP) Cohort. Environ Int. 2017;104:102-9.

31. Budhiraja R, Tuder RM, Hassoun PM. Endothelial dysfunction in pulmonary hypertension. N Engl J Med. 1992;327(2):117-9.

32. Windgassen EB, Funtowicz L, Lunsford TN, Harris LA, Mulvagh SL. C-reactive protein and high-sensitivity C-reactive protein: an update for clinicians. Postgrad Med. 2011;123(1):114-9.

33. Ali S, Stone MA, Peters JL, Davies MJ, Khunti K. The prevalence of comorbid depression in adults with type 2 diabetes: a systematic review and meta-analysis. Diabetic Med. 2006;23(11):1165-73.

34. Anderson RJ, Lustman PJ, Clouse RE, Groot MD, Freedland KE. Prevalence of depression in adults with diabetes: a systematic review. Diabetes. 2000;49:A64.

35. Lee YM, Kim HM, Lee MS, Lee HY. Measurement and determinants of mental health states for the urban poor. J Korean Neuropsychiatr Assoc. 1999:38(6):1234-44

36. National Bureau of Statistics of the People's Republic of China. Main data communiqu for the sixth national census in 2010; 2012. http://www.gov. cn/test/2012-04/20/content_2118413.htm. Accessed 28 Apr 2011.

37. Mirowsky J, Ross CE. Social patterns of distress. Annu Rev Sociol. 1986;12(4):23-45

38. Quesnel-Vallee A, Maximova K. Mental health consequences of unintended childlessness and unplanned births: gender differences and life course dynamics. Soc Sci Med. 2009;68(5):850-7.

39. Lee MA. Neighborhood residential segregation and mental health: a multilevel analysis on hispanic Americans in Chicago. Soc Sci Med. 2009:68(11):1975-84

40. Lam CL, Tse EY, Gandek B, Fong DY. The SF-36 summary scale were valid, reliable, and equivalent in a Chinese population. J Clin Epidemiol. 2005;58(8):815-22.

41. van der Meulen MJ, John MT, Naeije M, Lobbezoo F. The Dutch version of the Oral Health Impact Profile (OHIP-NL): translation, reliability and construct validity. BMC Oral Health. 2008:8:11. 
42. Kara B. Validity and reliability of the Turkish version of the thirst distress scale in patients on hemodialysis. Asian Nurs Res. 2013;7(4):212-8.

43. Aly NAEM. A valid and reliable egyptian nnstrument for identifying barriers influencing managing and improving quality in nursing service. Eur J Biol Med Sci Res. 2014;2(4):66-77.

44. Paul S, Bhattacharya RN. Energy intensity and carbon factor in $\mathrm{CO} 2$ emission intensity. J Environ Syst. 2003;29(4):269-78.

45. Jorgenson AK. Political-economic integration, industrial pollution and human health: a panel study of less-developed countries, 1980-2000. Int Sociol. 2009;24(1):115-43.

46. Drabo A. Impact of income inequality on health: does environment quality matter? Environ Plann A. 2011;43(1):146-65.

47. Li S, Zhang J, Ma Y. Financial development, environmental quality and economic growth. Sustainability. 2015;7(7):9395-416.

48. StataCorp. Stata statistical software: release 14. College Station: StataCorp, StataCorp LP; 2015.

49. Dales RE, Cakmak S. Does mental health status influence susceptibility to the physiologic effects of air pollution? a population based study of canadian children. PLoS ONE. 2016;11(12):e0168931.

50. Greene $\mathrm{WH}$. On the asymptotic bias of the ordinary least squares estimator of the tobit model. Econometrica. 1981;49(2):505-13.

51. Tansel A, Bircan F. Demand for education in Turkey: a tobit analysis of private tutoring expenditures. Econ Educ Rev. 2006;25(3):303-13.

52. Zijlema WL, Wolf $K$, Emeny R, Ladwig KH, Peters A, Hongsgard H, Hveem K, Kvaløy K, Yli-Tuomi T, Partonen T, Lanki T, Eeftens M, de Hoogh K, Brunekreef B, BioSHaRE SRP, Rosmalen JG. The association of air pollution and depressed mood in 70,928 individuals from four European cohorts. Int J Hyg Envir Heal. 2016;219(2):212-9.

53. Tzivian L, Winkler A, Dlugaj M, Schikowski T, Vossoughi M, Fuks K, Weinmayr G, Hoffmann B. Effect of long-term outdoor air pollution and noise on cognitive and psychological functions in adults. Int J Hyg Environ Health. 2015;218(1):1-11.

54. Hsu A, Esty DC, Levy MA, Sherbinin AD. 2016 Environmental Performance Index (EPI). Technical Report; 2016.

55. Kleinman KM, Goldman H, Snow MY, Korol B. Relationship between essential hypertension and cognitive functioning II: effects of biofeedback training generalize to non-laboratory environment. Psychophysiology. 1977;14(2):192-7.

56. Zhang J, Qian Z, Kong L, Zhou L, Yan L, Chapman RS. Effects of air pollution on respiratory health of adults in three chinese cities. Arch Environ Health. 1999;54(6):373-81.

57. Qian Z, Chapman RS, Tian Q, Chen Y, Lioy PJ, Zhang J. Effects of air pollution on children's respiratory health in three Chinese cities. Arch Environ Health. 2000;55(2):126-33.

58. Chen B, Hong C, Kan H. Exposures and health outcomes from outdoor air pollutants in China. Toxicology. 2004;198(1-3):291-300.

59. Kan H, Wong CM, Vichit-Vadakan N, Qian Z, PAPA Project Teams. Short-term association between sulfur dioxide and daily mortality: the Public Health and Air Pollution in Asia (PAPA) study. Environ Res. 2010;110(3):258-64.

60. Chen R, Pan G, Zhang Y, Xu Q, Zeng G, Xu X, Chen B, Kan H. Ambient carbon monoxide and daily mortality in three Chinese cities: the China Air Pollution and Health Effects Study (CAPES). Sci Total Environ. 2011;409(23):4923-8.

61. Kan H, Chen R, Tong S. Ambient air pollution, climate change, and population health in china. Environ Int. 2012;42:10-9.

62. Anderson JO, Thundiyil JG, Stolbach A. Clearing the air: a review of the effects of particulate matter air pollution on human health. J Med Toxicol. 2012;8(2):166-75.

63. Shang Y, Sun Z, Cao J, Wang X, Zhong L, Bi X, Li H, Liu W, Zhu T, Huang W. Systematic review of Chinese studies of short-term exposure to air pollution and daily mortality. Environ Int. 2013;54:100-11.

64. Voorhees AS, Wang J, Wang C, Zhao B, Wang S, Kan H. Public health benefits of reducing air pollution in Shanghai: a proof-ofconcept methodology with application to BenMAP. Sci Total Environ. 2014:485-486:396-405.
65. Tambo E, Wang DQ, Zhou XN. Tackling air pollution and extreme climate changes in China: implementing the Paris climate change agreement. Environ Int. 2016;95:152-6.

66. Musselman DL, Evans DL, Nemeroff CB. The relationship of depression to cardiovascular disease: epidemiology, biology, and treatment. Arch Gen Psychiatry. 1998;55(7):580-92.

67. Cole SM, Tembo G. The effect of food insecurity on mental health: panel evidence from rural Zimbabwe. Soc Sci Med. 2011;73(7):1071-9.

68. Rucci P, Gherardi S, Tansella M, Piccinelli M, Berardi D, Bisoffi G, Corsino MA, Pini S. Subthreshold psychiatric disorders in primary care: prevalence and associated characteristics. J Affect Disord. 2003;76(1-3):171-81.

69. Hanlon C, Medhin G, Alem A, Araya M, Abdulahi A, Hughes M, Tesfaye $M$, Wondimagegn D, Patel V, Prince M. Detecting perinatal common mental disorders in Ethiopia: validation of the self-reporting questionnaire and Edinburgh Postnatal Depression Scale. J Affect Disord. 2008;108(3):251-62

70. Liang J, Gu S, Krause N. Social support among the aged in Wuhan, China. Asia Pac Popul J. 1992;7(3):33-62.

71. Lippi G, Montagnana M, Favaloro EJ, Franchini M. Mental depression and cardiovascular disease: a multifaceted, bidirectional association. Semin Thromb Hemost. 2009;35(3):325-36.

72. Kiessling SG, Mcclanahan KK, Omar HA. A comprehensive approach to obesity, hypertension, and mental health evaluation. In: Omar H, Greydanus DE, Patel DR, Merrick J, editors. Adolescence and chronic illness: a public health concern. NY: Nova Science Publishers, Inc; 2010. p. 189-200.

73. Centers for Disease Control and Prevention. Mental health in the United States: health risk behaviors and conditions among persons with depression-new Mexico, 2003. MMWR Morb Mortal Wkly Rep. 2005;54(39):989-91.

74. Jonas BS, Franks P, Ingram DD. Are symptoms of anxiety and depression risk factors for hypertension? Longitudinal evidence from the National Health and Nutrition Examination Survey I Epidemiologic Follow-up Study. Arch Fam Med. 1997;6(1):43-9.

75. Rugulies R. Depression as a predictor for coronary heart disease. a review and meta-analysis. Am J Prev Med. 2002;23(1):51-61.

76. Renn BN, Feliciano L, Segal DL. The bidirectional relationship of depression and diabetes: a systematic review. Clin Psychol Rev. 2011;31(8):1239-46.

77. MA Healthcare Ltd. Depression leads to increased stroke risk. Independent Nurse. 2011;10:7.

78. Schwarz R. Stress and depression are not causes of cancer. Strahlenther Onkol. 1996:172(11):632-3.

79. Genen L, Davis JM. Chapter 55-Chronic lung disease: etiology and pathogenesis. Manual of neonatal respiratory care. Maryland Heights: Mosby, Inc.; 2006. p. 358-63.

80. Tahir A, Malik FR, Ahmad I, Akhtar P. Aetiological factors of chronic liver disease in children. J Ayub Med Coll Abbottabad. 2011;23(2):12-4.

81. Benjamin L, Frederick J. Autoimmune and chronic hepatitis. In: Kliegman $\mathrm{R}$, Behrman R, Jensen H, Santon B, editors. Nelson text book of paediatrics. Philadelphia: Saunders; 2007. p. 1698.

82. Evans PD, Taal MW. Epidemiology and causes of chronic kidney disease. Medicine. 2011;39(7):402-6.

83. A brief introduction to stomach diseases-causes, types, symptoms and treatment. Gcool health guides; 2016. http://www.coolhealthguide s.com/a-brief-introduction-to-stomach-disease-causestypessymptomsand-treatment.html. Accessed 29 Aug 2016.

84. Hernan MA, Brumback B, Robins JM. Marginal structural models to estimate the joint causal effect of nonrandomized treatments. J Am Stat Assoc. 2001;96(454):440-8.

85. Stieb DM, Burnett RT, Smith-Doiron M, Brion O, Shin HH, Economou V. A New multipollutant, no-threshold air quality health index based on short-term associations observed in daily time-series analyses. J Air Waste Manag Assoc. 2008;58(3):435-50. 